\title{
Indonesia: The midwife and maternal mortality miasma
}

I $\mathrm{t}$ is late evening and the lineup in the waiting room of the Iyet Maternity Centre in Bandung, Indonesia, begins to swell with pregnant women. Iyet Ratnasih, owner of the six-room facility and a "bidan praktek swasta" (midwife, private practice), will help to deliver 15-20 babies each month on the sparsely equipped but cheerful and squeaky clean premises in this city of 2.4 million once known as the "Paris of Java."

The volume of patients is spiralling, in part because of a recent decision to open up the facility to governmentinsured patients, though their pockets aren't as deep, Ratnasih says. "I want to be part of the solution to the crisis."

The crisis is in part the product of a solution gone awry.

Faced with maternal mortality levels on the order of 600 per 100000 live births in the 1980s, Indonesia launched a massive program in 1989 to train 60000 midwives and pay them to work in remote areas.

It worked, for a time. Maternal mortality rates began declining. But then many of the newly trained midwives began abandoning public service in favour of more lucrative private practice and the pool of government money available to train midwives spawned the creation of a host of substandard academies that produced poorly trained midwives. The decline in the maternal mortality rate slowed to a crawl. It was 220 per 100000 live births in 2010, or about 13.75 times the average in developed countries and 18.3 times the rate in Canada, according to the World Health Organization (www.unfpa.org /webdav/site/global/shared/documents /publications/2012/Trends_in_maternal _mortality_A4-1.pdf). The lifetime risk of maternal death is 1 in 150 for women in Indonesia, as compared with one in 4000 in developed nations.

Most of the deaths could be avoided if properly trained midwives like Ratnasih were available at every birth, says Dr. Gita Maya Koemara Sakti, director

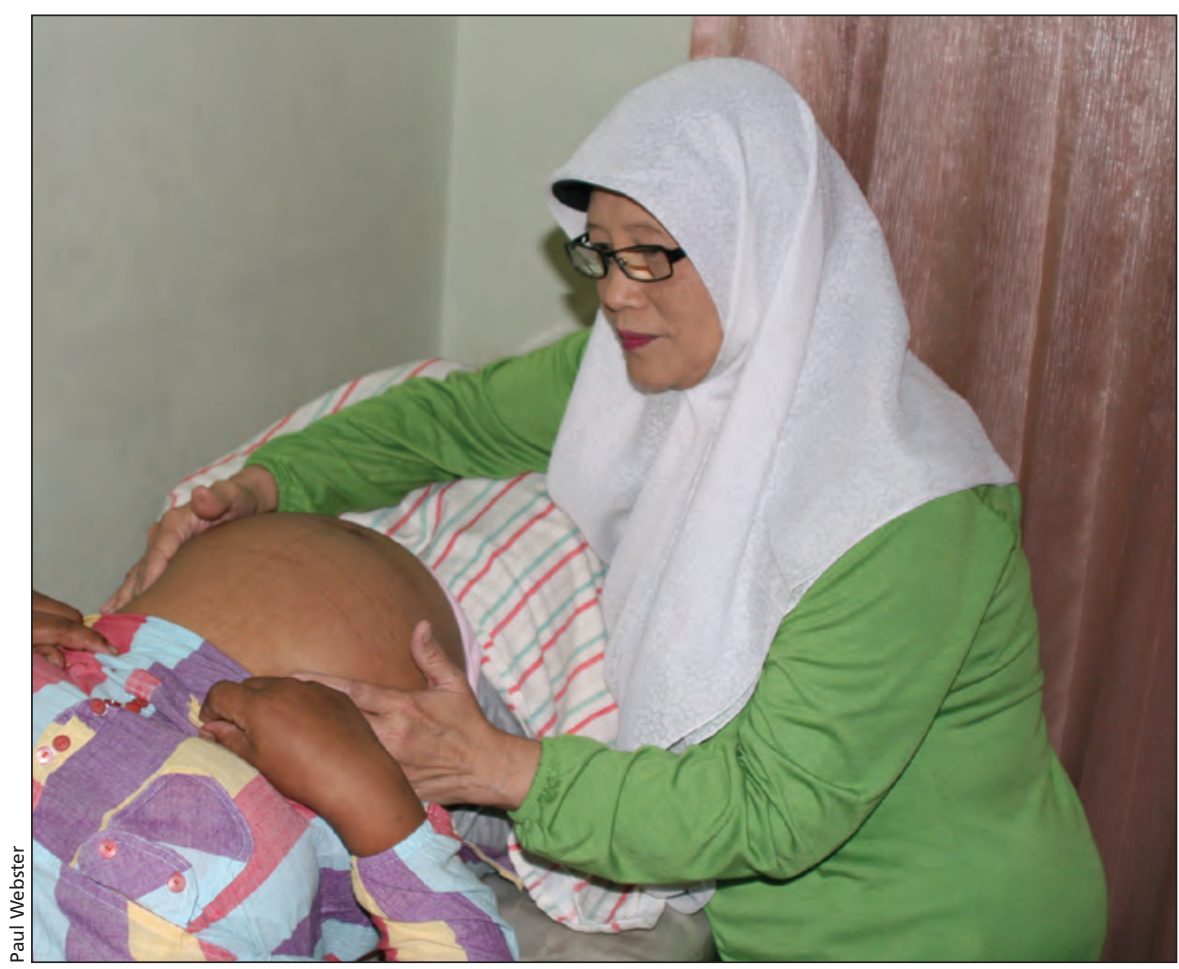

Midwife lyet Ratnasih helps to deliver 15 to 20 babies each month in Bandung, Indonesia.

of maternal health for the Indonesia Ministry of Health. "The biggest killers are hemorrhages, infections, and preeclampsia. We can stop them by providing more midwives and strengthening basic emergency obstetrical and neonatal care."

Surrounded by spreadsheets outlining national programs to reduce maternal deaths, Sakti says the aim is still to reduce the mortality rate to roughly 100 per 100 000, and thus honour a pledge to the United Nations. "We still have a lot of work to do but we have been making huge progress."

The original midwifery program certainly helped, Sakti says. "The idea was to place a midwife in every village in the country" and by the year 2000, the maternal mortality rate had been halved.

But as that decline reversed, critics of the program have risen in tandem.

The program stalled because huge numbers of government-trained midwives bailed for private practices that did not serve the poor, especially those living in remote areas, says Minim Ratminah, director of programming for the Indonesian Midwives Association. Some $50 \%$ of maternal deaths continue to occur in just 5 of Indonesia's 33 provinces "because midwives won't work in them and pregnant women remain unconvinced they need assisted delivery. They continue to see birthing as a natural process that family members can handle, perhaps with assistance from traditional village healers who will not refer women to medical facilities in emergencies."

As problematic are the scores of substandard academies that sprung up in response to government subsidies, adds Ratminah, who served as director of maternal health for the densely populated province of West Java until 2006. They're producing poorly trained midwives and their operations have become the foundation for numerous corruption charges, she notes.

Licences for the academies are 
issued by the ministry of education, not the ministry of health, Ratminah adds. "You can easily buy a licence and there really is no certification or inspection of the hundreds of new academies."

"Somebody has to shut these schools down," argues Anne Hyre, director of a United States governmentfunded program developed by the Johns Hopkins Program for International Education in Gynecology and Obstetrics (Jhpiego) to bolster training in 150 hospitals and 300 community health centres so as to reduce maternal mortality rates. "There are now roughly 750 academies churning out 40000 graduates a year. And many of these graduates have never touched a body. These students are being misled."

Jhpiego has partnered with the private Budi Kemuliaan Hospital and Midwifery Academy in the Indonesian capital of Jakarta to create a national centre for leadership in maternal health that hopes to improve clinical training for midwives, nurses and physicians, as well as the management of public hospitals.

"We have stopped making progress to reduce maternal mortality," says Dr. Mohammad Baharuddin, director of the midwifery school at Budi Kemuliaan. "To resume progress we need to create competence, character and culpability in public hospitals. We have to modernize emergency obstetrical care and make it available to the huge numbers of women who currently get none."

Sakti hopes the cause will also be advanced by a relaunch of the national midwifery program that will include the use of financial incentives to encourage 72000 traditional birthing attendants to work in remote villages, in partnership with midwives whenever possible.

The government has also opened 2800 "waiting homes" near medical clinics where rural women can stay under supervision from midwives, while providing a sixfold increase in funding for 9000 health clinics over the past two years, Sakti adds.

Moreover, the national social assistance program has been extended to include free maternal care in private facilities such as Ratnasih's maternity centre. Women who cannot pay for private deliveries now have an option of getting the aid of a properly trained bidan praktek swasta, Sakti says. "We know that this will save large numbers of lives." - Paul Christopher Webster, Bandung, Indonesia

CMAJ 2013. DOI:10.1503/cmaj.109-4347 